\title{
Improvement of Power Transformers by using Mixtures of Mineral Oil with Synthetic Esters
}

\author{
C. Perrier \\ AREVA T\&D, ARC \\ 130 rue Leon Blum, 69611 Villeurbanne, France \\ A. Beroual \\ Ecole Centrale de Lyon, CEGELY CNRS UMR 5005 \\ 36 avenue Guy de Collongue, 69134 Ecully, France \\ and J-L. Bessede \\ AREVA T\&D, ARC \\ 130 rue Leon Blum, 69611 Villeurbanne, France
}

\begin{abstract}
This paper is aimed at the optimization of power transformer insulation via the improvement of the characteristics of the most commonly used insulating liquid, i.e., mineral oil. For that purpose, mixtures consisting of mineral oil and other insulating liquids (namely silicon and synthetic ester oils) are investigated. The main properties such as the heat transfer, breakdown voltage (BDV), aging stability and electrostatic charging tendency (ECT) of different mixtures as well as the liquids alone are compared. The heat transfer is studied by means of kinematic viscosity. The measurements of breakdown voltage are analyzed by means of Gaussian probabilities. The results of aging tests at controlled temperature and in contact with atmosphere are presented, as well as the ECT effect versus the oil humidity and resistivity. It is shown that the best mixture enabling optimization of the power transformer insulation, (i. e. improving the dielectric properties and the aging stability of mineral oil without degrading its viscosity and ECT), is that of mineral oil with $20 \%$ by volume of synthetic ester oil.
\end{abstract}

Index Terms - Power transformers, oil mixtures, breakdown, heat transfer, aging, electrical charge tendency.

\section{INTRODUCTION}

THE improvement of the characteristics of power transformers is an ongoing duty for manufacturers, since these equipments constitute one of the most expensive and strategic components of electric power transmission and distribution systems. Any failure of such components can result in significant economic losses. So, the manufacturers need to improve the reliability of these equipments and reduce their costs by: (i) reducing their size, requiring smaller insulating gaps which lead to higher heat densities to cool, and (ii) increasing their life cycle.

In order to improve power transformer reliability, a special focus has been carried out on insulating materials and especially on insulating oils. The majority of high voltage

Manuscript received on 8 September 2005, in final form 27 January 2006 transformers are filled with liquids that work as an electrical insulation as well as a heat transfer medium. Thus, for a transformer with a smaller size (by means of a reduced insulation gap), the liquids have to ensure the integrity of this gap for the existing or even higher voltage levels, and to enable the cooling to be still effective. The most commonly used liquid in power transformers is mineral oil [1] due to its low price and its good properties. However the performance of mineral oil starts to be limited with respect to the new (above) requirements. For that purpose, numerous activities have been initiated to try to improve the properties of mineral oil or to find other substitute liquids.

This paper is aimed at the optimization of power transformer insulation via improvement of the characteristics of mineral oil. For that purpose, mixtures consisting of mineral oil and two other kinds of insulating liquids (namely silicon and 
synthetic ester oils) are investigated. These three liquids (mineral, silicon and synthetic ester oils), as well as their mixtures, are analyzed and compared on the basis of the main properties required for an insulating liquid for power transformers. These are heat transfer, breakdown voltage (BDV), aging stability and electrostatic charging tendency (ECT). Different mixtures were considered. However, the emphasis has been put on the mixtures based on $80 \%$ of mineral oil with $20 \%$ of another fluid. This proportion appears to be the best compromise from a technical and economical point of view.

We first show that the kinematic viscosity is the most influential parameter for the transfer of heat. Then we review this parameter in accordance with ISO 3104 specification. With respect to BDV, the measurements are performed according to IEC 60156 specifications and analyzed by means of Gaussian probabilities. The oxidation stability is studied through the analysis of acidity and loss factor $(\tan \delta)$, with the aging tests being carried out at constant temperature and in contact with the atmosphere in accordance with ASTM D1934. Finally, the evolution of ECT by different oils and mixtures is investigated using a "Mini-static" charge tester; the ECT results are correlated to humidity content and resistivity.

\section{EXPERIMENTS 2.1 TESTED PRODUCTS}

Firstly, the different constituents of the mixtures under consideration are described. They are:

(1) A non-inhibited napthenic mineral oil (A), which is frequently used in power transformers for its better pour point and gas-absorbing properties than paraffinic oils.

(2) Two synthetic ester oils (tetraesters), (B) and (C), based on pentaerythritol and frequently used in distribution and traction transformers for their high fire resistance. These oils were chosen for their high water solubility, their pour point close to that of mineral oil and their better oxidation stability than vegetable oils [2].

(3) A silicon oil (D), based on polydimethylsiloxane and frequently used in distribution and traction transformers for its high fire resistance and its high thermal stability. It has a high aging stability [3].

The properties of these liquids are given in Table 1.

Table 1. Insulating oils properties (supplier values).

\begin{tabular}{|c|c|c|c|c|}
\hline \multirow{2}{*}{ Properties (IEC) } & \multicolumn{4}{|c|}{ Type of Oil } \\
\cline { 2 - 5 } & $\begin{array}{c}\text { Napthenic } \\
\text { Mineral oil } \\
(\text { A })\end{array}$ & $\begin{array}{c}\text { Synthetic } \\
\text { Ester oil } \\
\text { ( B })\end{array}$ & $\begin{array}{c}\text { Synthetic } \\
\text { Ester oil } \\
(\mathrm{C})\end{array}$ & $\begin{array}{c}\text { Silicon } \\
\text { Oil } \\
(\mathrm{D})\end{array}$ \\
\hline Density $\left(20^{\circ} \mathrm{C}\right) \mathrm{g} / \mathrm{cm}^{3}$ & 0.89 & 0.97 & 0.99 & 0.96 \\
\hline Viscosity $\left(40^{\circ} \mathrm{C}\right) \mathrm{mm}^{2} / \mathrm{s}$ & 8.9 & 30 & 33 & 35 \\
\hline Pour point ${ }^{\circ} \mathrm{C}$ & -57 & -48 & -51 & -50 \\
\hline Thermal conductivity $\left(20^{\circ} \mathrm{C}\right) \mathrm{W} / \mathrm{m} . \mathrm{K}$ & 0.13 & 0.16 & 0.14 & 0.15 \\
\hline Flash point ${ }^{\circ} \mathrm{C}(\mathrm{PM}$ method) & 148 & 257 & $>250$ & 305 \\
\hline Dissipation factor $\left(90^{\circ} \mathrm{C}\right)$ & $<0.001$ & 0.004 & 0.02 & $<0.001$ \\
\hline Dielectric constant $\left(20^{\circ} \mathrm{C}\right)$ & 2.2 & 3.2 & 3.3 & 2.7 \\
\hline Breakdown voltage $-\mathrm{kV}$ & $>70$ & $>75$ & $>75$ & $>50$ \\
\hline Max. water solubility $\left(25^{\circ} \mathrm{C}\right) \mathrm{ppm}$ & 70 & 2500 & 2500 & 200 \\
\hline
\end{tabular}

\subsection{MISCIBILITY}

To study the miscibility of mixtures, two types of analysis were conducted: (i) a qualitative analysis to check the homogeneity of the mixtures (i.e., the non-existence of emulsion); and (ii) analysis of the compatibility to check the evolution of the characteristics of the mixtures. The first part of this study consists of creating mixtures of mineral oil with $10 \%, 20 \%, 50 \%$ and $90 \%$ (in volume) of the other fluids. Each mixture is then put in a closing vessel and submitted to three ageing stages; initially at $105{ }^{\circ} \mathrm{C}$ for $168 \mathrm{~h}$, then at room temperature for 21 days and finally at $-40{ }^{\circ} \mathrm{C}$ for $3 \mathrm{~h}$. Afterwards, the homogeneity and the acidity were checked. The second part consists of analysing the characteristics of the mixture (i.e., BDV, heat transfer, ageing stability and ECT) in comparison to the mineral oil alone. In addition, for each one of these characteristics, the experimental results are compared to the calculated values according to the mixture law (proportionality law), given by the following relationship

$$
\Psi_{C}=X \frac{\Psi_{A}}{100}+Y \frac{\Psi_{B}}{100}
$$

where, at a given temperature and in the same conditions, $X$ is the $\%$ by volume of an oil A with a characteristic $\Psi_{A}$, Y is the $\%$ by volume of an oil B with a characteristic $\Psi_{B}$, and $\mathrm{C}$ is the mixture of A and B with a characteristic $\Psi_{C}$.

\subsection{HEAT TRANSFER}

Heat transfer is one of the essential functions that has to be provided by the insulating fluid because of the high thermal stresses usually found in power transformers.

This function is realized by both thermal conductivity and convection [4]. The convection represents all of the properties that lead to the heat transfer by fluid displacement (viscosity, specific heat, thermal expansion coefficient), whereas the thermal conductivity is realised within a fluid displacement. The heat transfer can be evaluated by the following relationship [5]

$$
P=\frac{C_{p} \lambda \alpha}{v}
$$

where $P$ is the cooling criteria, $C_{P}$ is the specific heat, $\lambda$ is the thermal conductivity, $\alpha$ is the thermal expansion coefficient and $v$ is the kinematic viscosity.

$P$ is a comparison criterion enabling the analysis of different products. The higher $P$ is, the better the heat transfer is. By comparing $P$ for the different characteristics appearing in equation (2), and using the supplier's values, it is observed that the kinematic viscosity is the most influential parameter for the transfer of heat (Figures 1 and 2), compared to the thermal conductivity (Figure 3 ) and the specific heat. The influence of the expansion coefficient is very low. Therefore, the heat transfer will be studied by comparisons of viscosity and measured in accordance with IEC 60296 / ISO 3104 specifications. The parameter $Q$, which enables the determination of the variations of viscosity versus temperature, is also analysed. Q is the ratio of two different viscosities. 


$$
Q=\frac{v_{1}\left(T_{1}\right)}{v_{2}\left(T_{2}\right)}
$$

where $v_{1}$ and $v_{2}$ are the values of viscosity at temperatures $T_{1}$ and $T_{2}$ respectively $\left(T_{1}<T_{2}\right)$.

The higher $Q$ is, the higher the viscosity variation is with temperature.

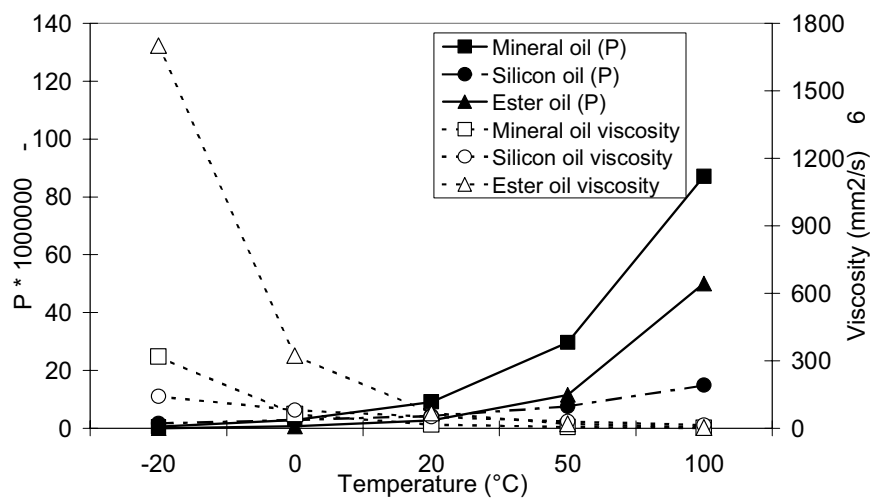

Figure 1. Influence of temperature on $\mathrm{P}$ and viscosity.

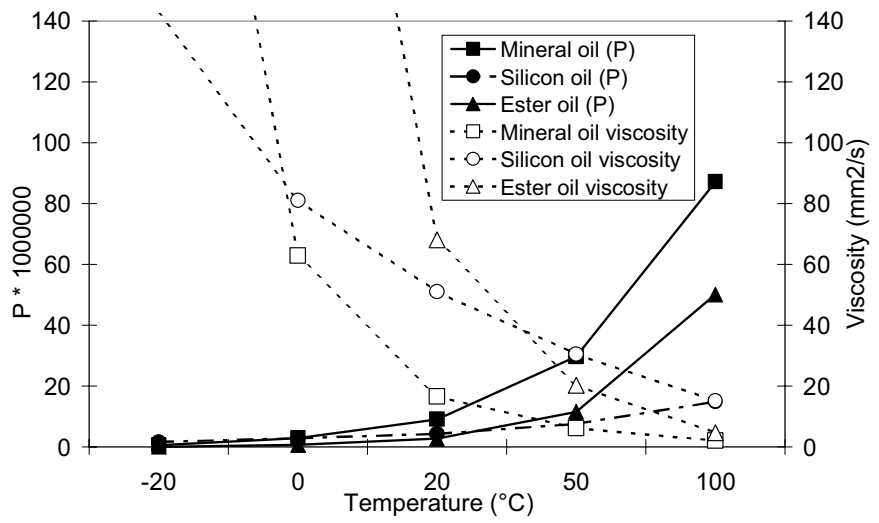

Figure 2. Influence of temperature on $\mathrm{P}$ and viscosity (zoom).

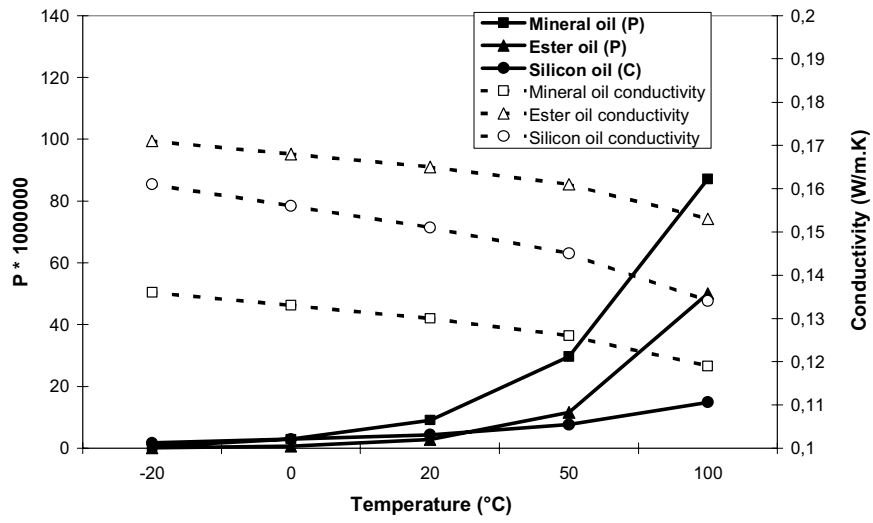

Figure 3. Influence of temperature on $P$ and thermal conductivity.

\subsection{BREAKDOWN VOLTAGE}

Breakdown voltage (BDV) measurements are achieved at room temperature, according to the IEC 60156 specification, i.e., under a quasi-uniform electric field obtained with spherical electrodes having a horizontal axis. The gap was set to $2.5 \pm 0.05 \mathrm{~mm}$. The voltage is uniformly increased $(2.0 \pm$ $0.2 \mathrm{kV} / \mathrm{s}$ ) and the oil is stirred during all the tests. A Baur Dieltest $(100 \mathrm{kV}-50 \mathrm{~Hz})$ device is used. Before each test, the samples are treated by means of an 11-16 $\mu \mathrm{m}$ sintered glass filter under vacuum $\left(10^{2} \mathrm{~Pa}\right)$. All samples are processed in the same conditions, i.e. they don't have specific treatment to create the same relative saturation (percentage of saturation with respect to the oil solubility at a given temperature). The oil water content is determined using the Coulometric Karl Fisher titration method (IEC 60814). The particle content is counted and classified according to IEC 60970 by means of an automatic laser microscope and NAS 1638 specifications (Table 2) respectively.

Table 2. Class of particulate pollution according to NAS 1638 for oil.

\begin{tabular}{|c|c|c|c|c|c|c|c|c|c|c|c|c|}
\hline Size & \multicolumn{10}{|c|}{ Class of particulate pollution } \\
\cline { 2 - 14 }$(\mu \mathrm{m})$ & 1 & 2 & 3 & 4 & 5 & 6 & 7 & 8 & 9 & 10 & 11 & 12 \\
\hline$[2.5]$ & 2500 & 5000 & 10000 & 20000 & 40000 & 80000 & 160000 & 320000 & 640000 & 1280000 & 2560000 & 5120000 \\
\hline$[5-15]$ & 500 & 1000 & 2000 & 4000 & 8000 & 16000 & 32000 & 64000 & 128000 & 256000 & 512000 & 1024000 \\
\hline$[15-25]$ & 89 & 178 & 356 & 712 & 1425 & 2850 & 5700 & 11400 & 22800 & 45600 & 91200 & 182400 \\
\hline$[25.50]$ & 16 & 32 & 63 & 126 & 253 & 506 & 1012 & 2025 & 4050 & 8100 & 16200 & 32400 \\
\hline$[50-100]$ & 3 & 6 & 11 & 22 & 5 & 90 & 180 & 360 & 720 & 1440 & 2880 & 5760 \\
\hline$\geq 100$ & 1 & 1 & 2 & 4 & 8 & 16 & 32 & 64 & 128 & 256 & 512 & 1024 \\
\hline
\end{tabular}

The measurements of breakdown voltage are conducted on oil samples having no particles larger than $100 \mu \mathrm{m}$. Thus, the influence of the particles is considered as being negligible with respect to the class of particulate pollution we obtained for each sample [6]. Also, the IEC 60156 method is not sufficiently sensitive to oil particle contamination [7] to be influenced by particles of this size present in the samples.

The BDV results are characterized by means of the cumulative Gaussian probabilities approach, which seems to be the most appropriate method. This approach is explained in the Experimental Results section.

\subsection{AGING / OXIDATION}

The quality of the insulation and heat transfer within a transformer depends on the quality of the constituents of the insulating structure, i.e. paper and oil. Oil degradation or oxidation which depends on temperature, oxygen and humidity, is a serious problem since it degrades the properties of paper and can lead to transformer failure, resulting in significant economic losses. Oxygen and humidity, which are already present in oil, also come from the atmosphere, especially in power transformers, which are generally free breathing. In order to study the aging influence on different oils and mixtures in conditions close to those existing in free breathing power transformers, three different ageing tests were carried out in accordance with ASTM D1934. This specifies the ageing of oils for $96 \mathrm{~h}$ in a circulating-air oven controlled at $115^{\circ} \mathrm{C}$.

The first ageing test is carried out on the samples alone, in order to have a reference evaluation. The second one is carried out in the presence of copper wire $(8.8 \%$ by weight of oil, according to IEC $61125 / \mathrm{A}$ ) to speed up the oxidation reaction, 
and the last one in the presence of Kraft insulating paper $(15 \%$ by weight of oil) dried and impregnated as for service conditions. The acidity and $\tan \delta$, which are the most pertinent properties to evaluate the oxidation $[8,9]$, are measured before and after each aging test.

\subsection{ELECTROSTATIC CHARGING TENDENCY}

In large power transformers, oil is forced to circulate through the transformer in order to cool the heat generated by the windings (that contain paper) and the core. However, the oil circulation results in a separation of charge at the paper/oil interface and in the appearance of a double layer of charge. This phenomenon can lead to charge accumulation, which then causes the initiation of partial discharges and can even lead to the breakdown of the transformer. Generally, the insulating oil is charged positively and the solid insulating material negatively $[10,11]$. The ECT of fluids is estimated by using a simple set-up that is called a "Mini-static" charge tester [10]. This test consists of forcing the fluid through a filter sheet in order to create a charge separation. The charge on the paper filter (Whatman 541) is measured by an electrometer. The most convenient unit to describe the ECT of oil is the charge density, i.e., the amount of charge generated per unit volume of oil in the flow.

$$
\rho=\frac{i t}{V} 10^{12}=\left[\frac{i}{(V / t)}\right] 10^{12}
$$

where $\rho$ is the charge density $\left(\mu \mathrm{C} / \mathrm{m}^{3}\right), i$ is the average current (A), $t$ is the time (s) and $V$ is the oil volume $(\mathrm{ml})$.

The ECT of different oils and mixtures, the influence of humidity on ECT and the correlation between the oil resistivity and charge density are studied. The measurement of resistivity is carried out in accordance with IEC 60247, using a threeterminal cell. The treatment to reduce the oil humidity is realised in the same manner as for the BDV test.

\section{EXPERIMENTAL RESULTS}

\subsection{MISCIBILITY}

It is observed that all the mixtures are homogeneous before and after ageing. No abnormal evolution of acidity occurred. In the following sections, the compatibility of the different mixtures is analysed by considering the heat transfer, the breakdown voltage, the evolution of acidity and $\tan \delta$ after ageing tests in contact with the atmosphere, and the electrostatic charging tendency results.

\subsection{KINEMATIC VISCOSITY}

The mineral oil appears to be the most efficient for the transfer of heat at positive temperatures and more particularly at transformer running temperatures $\left(80\right.$ to $\left.90{ }^{\circ} \mathrm{C}\right)$ contrarily to silicon oil, which is the least efficient at temperatures above ambient (Figure 4). However, it is noted that silicon oil has a good viscosity index and thus presents a better viscosity at negative temperatures. Indeed, the parameter $Q$ of silicon oil remains stable contrary to the $Q$ for the other tested oils (Figure 5). Ester oil has a high viscosity at temperatures below the ambient temperature (Figures 4 and 5).
From these results, it is interesting to note that adding $20 \%$ of ester oil does not affect the mineral oil viscosity. Indeed, the viscosity of such a mixture remains very close to that of mineral oil alone. This is connected to the fact that the oil mixtures do not follow the "mixture law", expressed by equation (1), due to chemical interactions between liquids (Figure 6). These results confirm those reported in literature $[12,13]$.

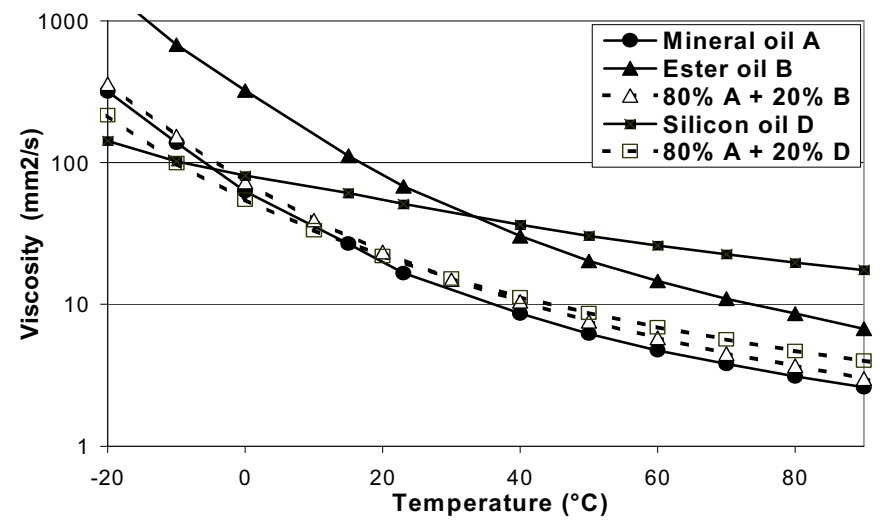

Figure 4. Variation of viscosity with temperature.

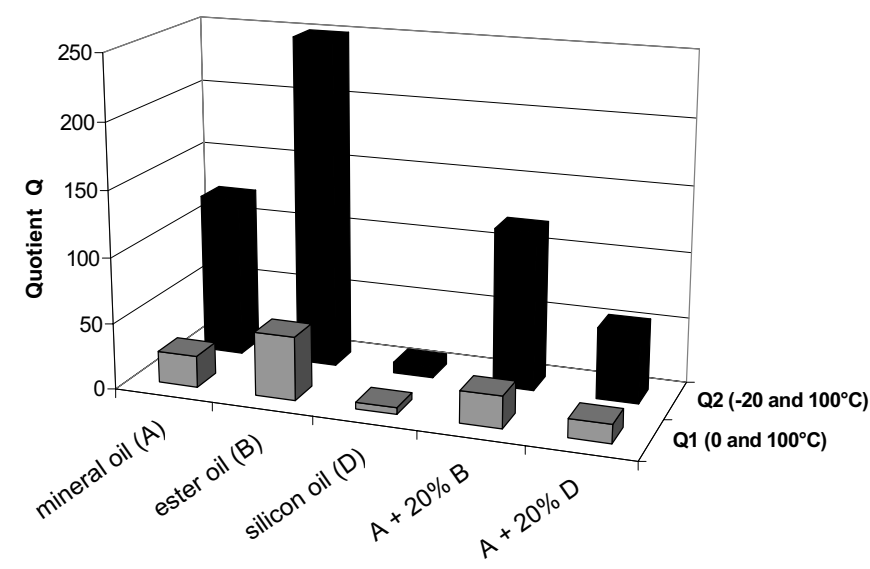

Oil and mixture types

Figure 5. Variation of viscosity with temperature, represented by the quotient $Q$ (see relationship 3).

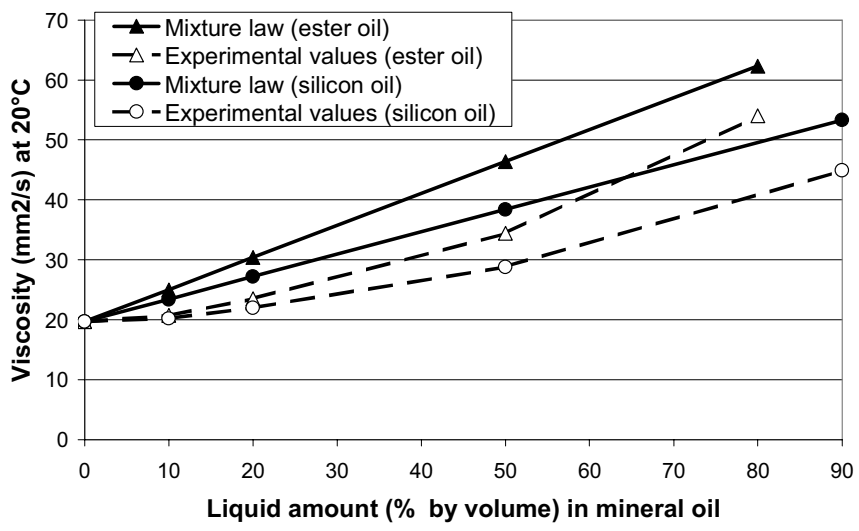

Figure 6. Comparison between the calculated viscosity (mixture law) and the experimental measurements. 


\subsection{BREAKDOWN VOLTAGE}

The BDV probability curves (Figures 7 and 8), achieved on 32 measurements, show the same tendency as the Gaussian curves (normal law) (Figure 9).

So we represented the BDV results by mean of the Gaussian probabilities. Specifically, we used the cumulative Gaussian probabilities, represented by equation (5), as it is the most appropriate one to determine the security coefficient (SC). The $\mathrm{SC}$ is the voltage (at $99.9 \%$, i.e., for $\mathrm{P}=0.001$ occurrence) below which the oil doesn't breakdown.

$$
P(U)=\frac{1}{\sigma \sqrt{2 \pi}} \int_{-\infty}^{U} \exp \left[-\frac{1}{2}\left(\frac{U_{i}-U_{M}}{\sigma}\right)^{2}\right] d u
$$

where $U_{i}$ is the $\mathrm{BDV}, U_{M}$ is the $\mathrm{BDV}$ average and $\sigma$ is the standard deviation.

The Henri's values $\left(u_{i}\right)$ are computed from eq. (6) according to Henri's law [14] (Figures 10 and 11) and are aligned on the same straight lines. Thus, it is confirmed that the BDV results follow a normal distribution.

$$
u_{i}=\frac{U_{i}-U_{M}}{\sigma}
$$

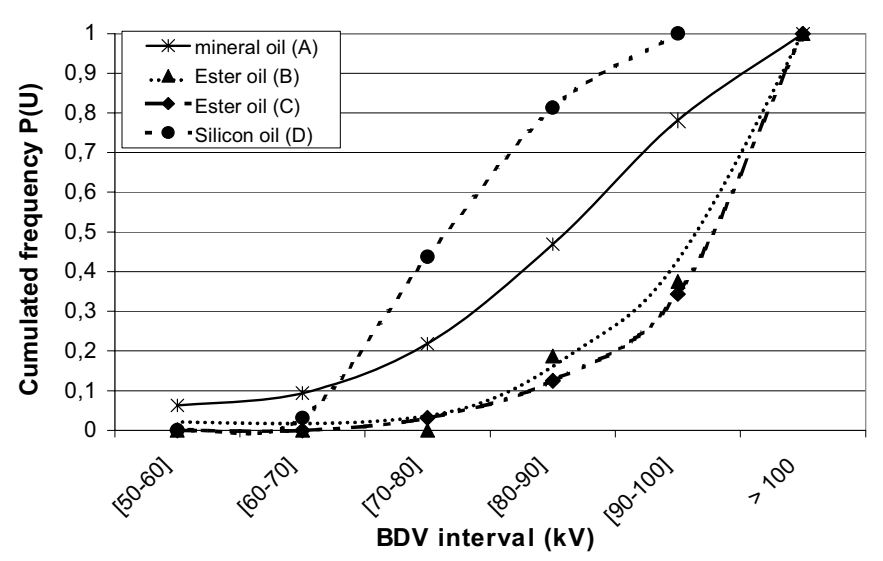

Figure 7. BDV probability curves on 32 measurements for oils alone

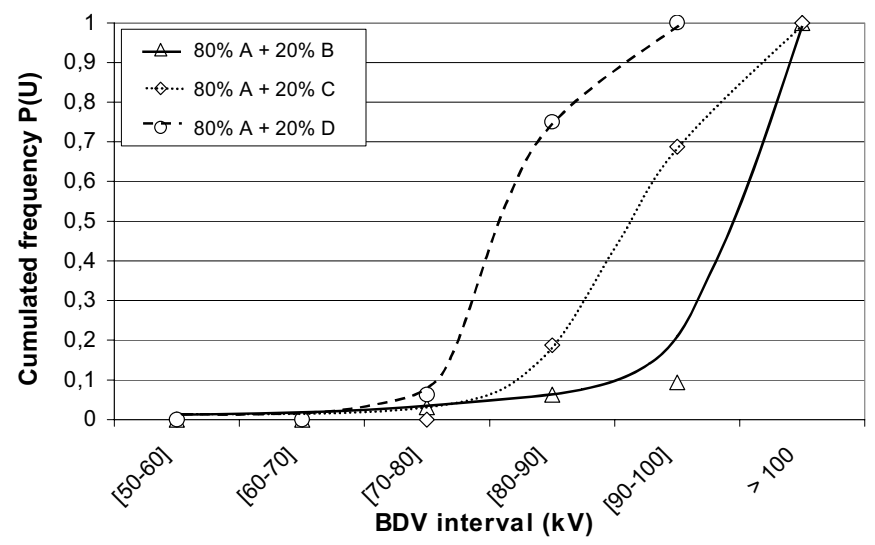

Figure 8. BDV probability curves on 32 measurements for mixtures

It appears from Figure 12 that silicon oil is less efficient than the other tested oils; it has the lowest average value. Ester oils have the higher BDV values (the mean values of the synthetic ester Gaussian curves are shifted to the right) and higher SC values (the Gaussian curves cut the voltage axis at higher values). Mineral oil is in between, but presents the lowest SC value. Specifically, for a voltage of $80 \mathrm{kV}, 40 \%$ of silicon oil and $25 \%$ of mineral oil samples have already broken down, while all samples of the synthetic ester oils have yet to fail. The higher dielectric strength of synthetic ester oil is connected to its high water saturation limit (see Table 1). In contrast, the lower SC value of mineral oil is connected to its low saturation limit. Figure 13 shows that the BDV of mineral and silicon oils is more sensitive to ageing than those of ester oils.

It is interesting to note that an addition of $20 \%$ of synthetic ester oil improves the BDV average value of mineral oil as well as its SC (Figure 14), and limits the reduction of its dielectric strength after ageing (Figure 15). These results also show that BDV does not follow the "mixture law"; they confirm that, in addition to the chemical interactions that can exist between both liquids, BDV depends considerably on the water content [15]. Indeed, ester oils have high water solubility and thus reduce the influence of humidity on mineral oil, as reported in literature [12].

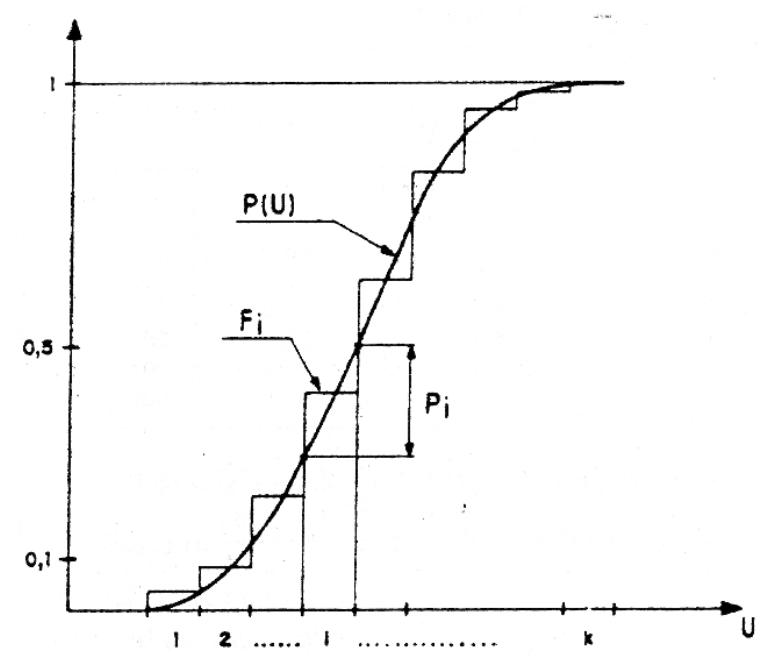

Figure 9: Cumulated frequency for an ideal sample following a normal. distribution $\left(F_{i}=\sum_{i=1}^{i} f_{i}=\sum_{i=1}^{i} \frac{n_{i}}{n}\right.$ with $\left.\sum_{i=1}^{k} n_{i}=n\right)$ [14]

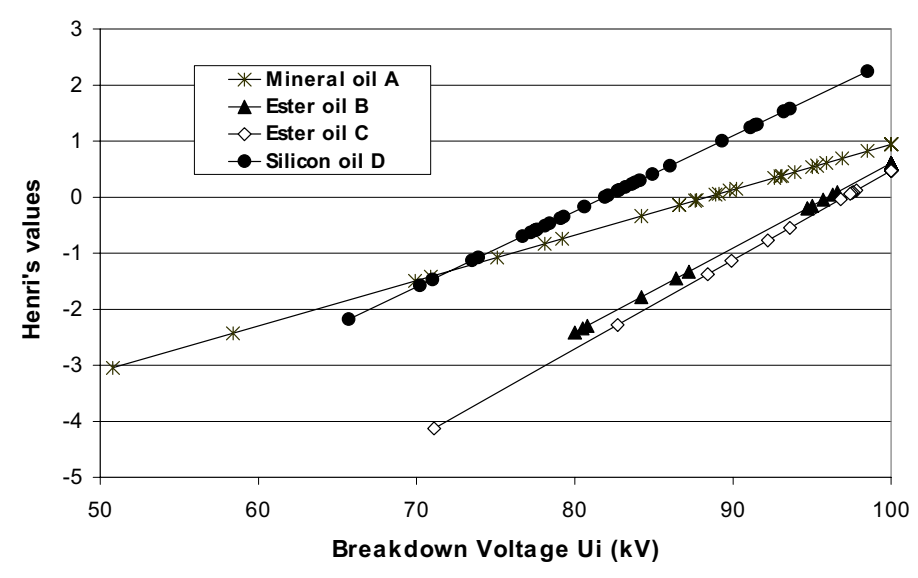

Figure 10. Henri's straight lines on 32 measurements for oils alone. 


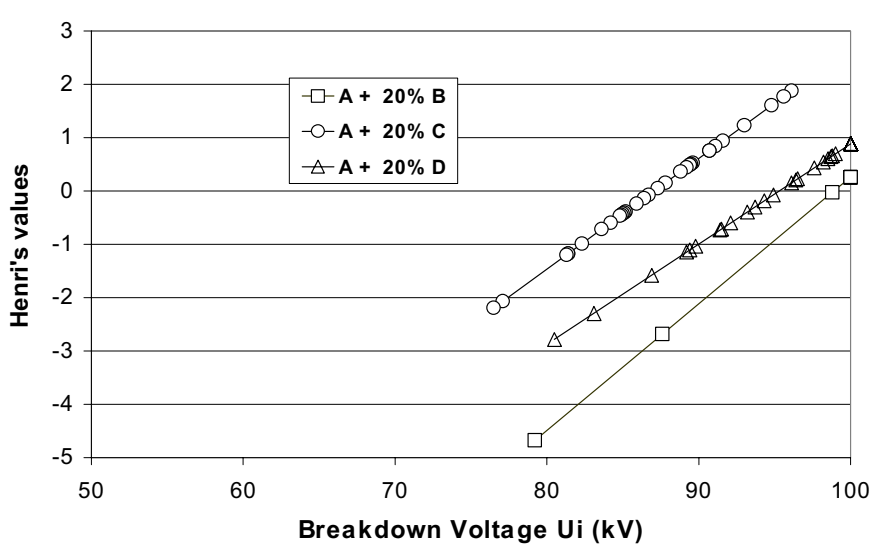

Figure 11. Henri's straight lines on 32 measurements for mixtures.

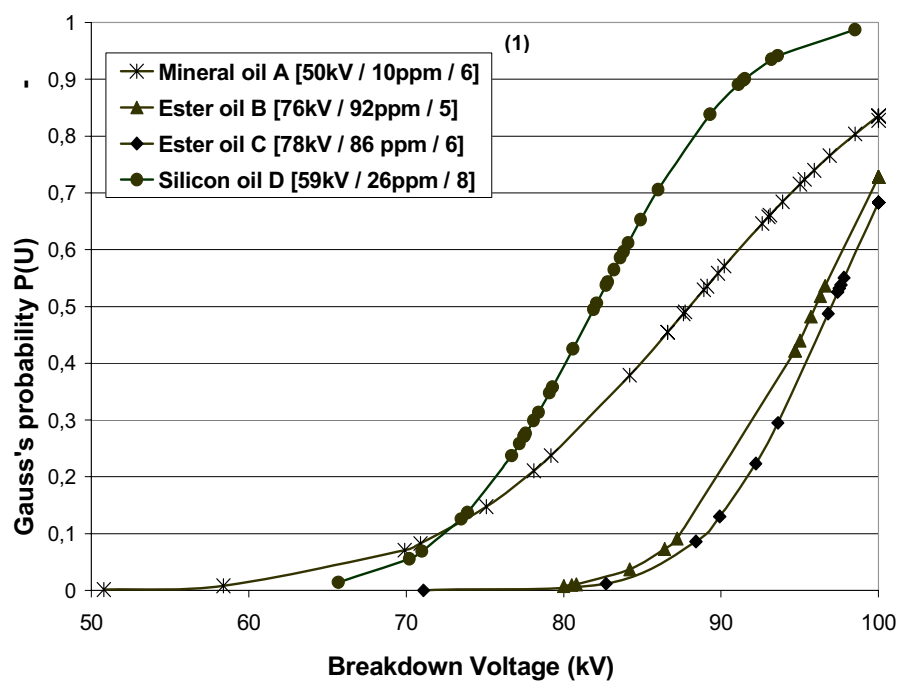

Figure 12. Probability study on BDV for oils alone with 32 measurements.

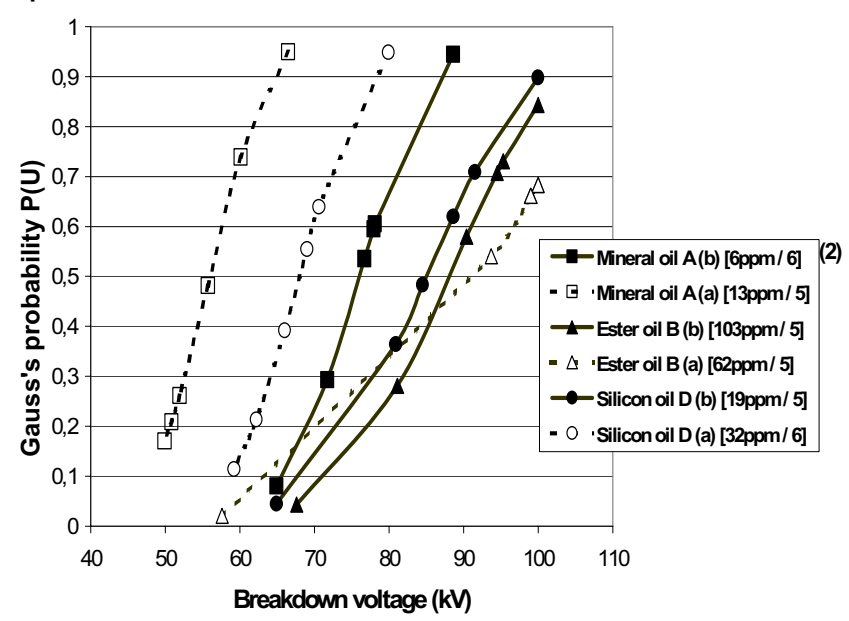

Figure 13. BDV evolution of oils alone, before (b) and after (a) ageing of products alone (ageing 1, c. f. §2.5), with 6 measurements.

\subsection{OXIDATION STABILITY}

It appears from Figures 16 and 17 that silicon oil is the most stable. Indeed, its $\tan \delta$ and acidity values do not notably increase. In contrast to silicon oil, mineral oil is the most sensitive to these ageing tests, and ester oil is in between. Note that the addition of $20 \%$ of ester oil (ester oil B in particular) to mineral oil reduces the ageing by decreasing the acidity and the rise of $\tan \delta$ (Figures 18 and 19). Silicon oil has an insignificant effect on the acidity of mineral oil when both are mixed. It is again noted that the "mixture law" is not applicable and mainly depends on the chemical interactions between oils. This case can be observed for the mixture with silicon oil. Indeed, silicon oil on its own has good oxidation stability, but its addition does not improve the oxidation stability of mineral oil.

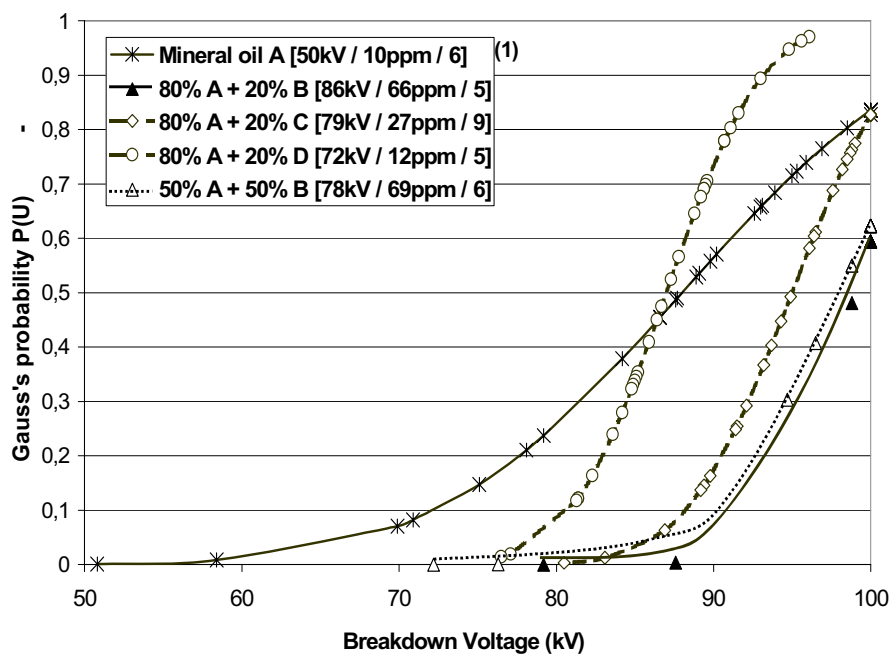

Figure 14. Probability study on BDV for mixtures with 32 measurements. (1) $[\mathrm{SC}(\mathrm{kV}) /$ water content $(\mathrm{ppm}) /$ class of particulate pollution]

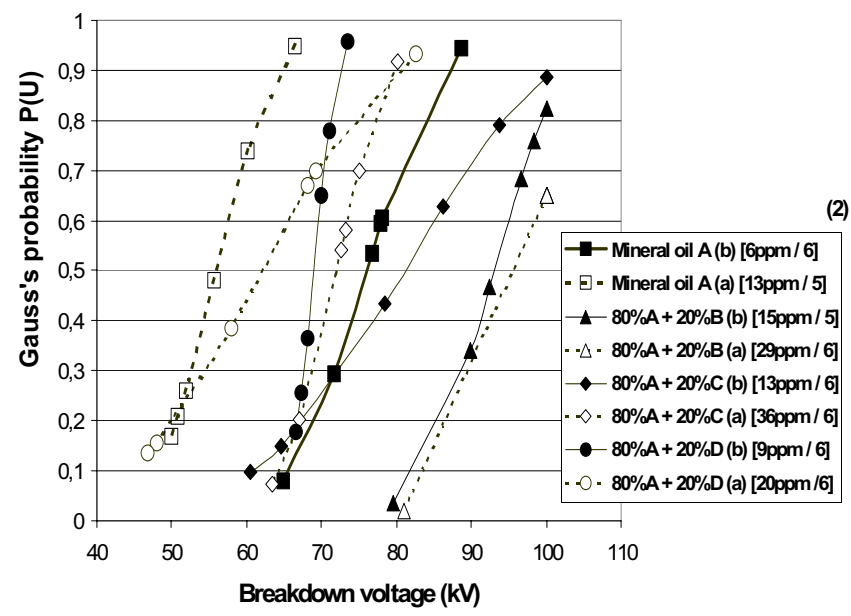

Figure 15. BDV evolution of mixtures, before (b) and after (a) ageing of products alone (ageing 1, c. f. §2.5), with 6 measurements.

(2): [water content (ppm)/ class of particulate pollution].

\subsection{ELECTROSTATIC CHARGING TENDENCY}

Figure 20 shows that ester oils have a high charging tendency, whereas mineral and silicon oils have a lower ECT. Mineral oil/ester oil mixtures give values in between those for the unmixed fluids. However, these values are moderate in comparison to ester oils alone. Note that again the "mixture law" is not followed. It is also observed that the ECT of each 
fluid is lower when its humidity content is higher (before treatment, as the treatment reduces the water content in the liquid). This influence of humidity seems to be more important for silicon oil. The ECT of oil is connected to its resistivity (Figure 21), and the higher the resistivity is, the lower the charging tendency is of the oil.

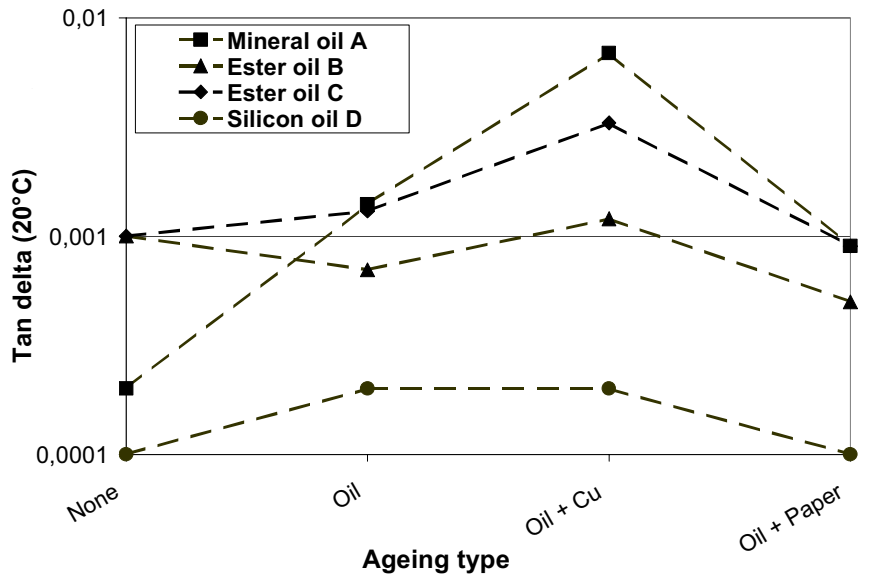

Figure 16. Tan $\delta$ evolution versus different ageing, for oils alone.

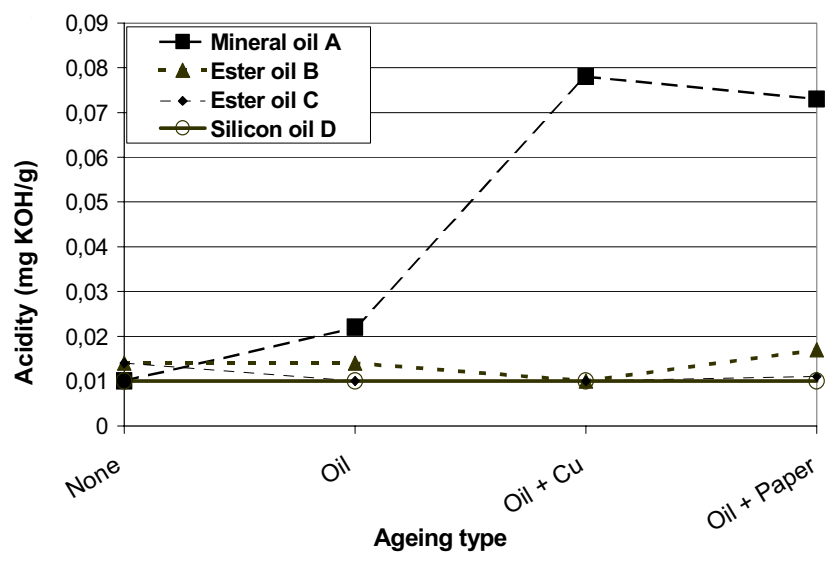

Figure 17. Acidity evolution versus different ageing, for oils alone.

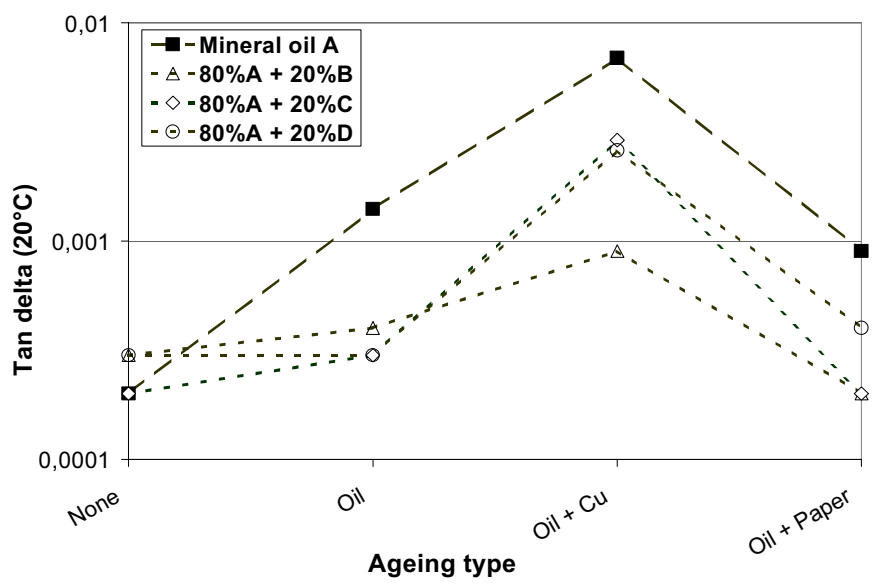

Figure 18. Tan $\delta$ evolution versus different ageing, for mixtures.

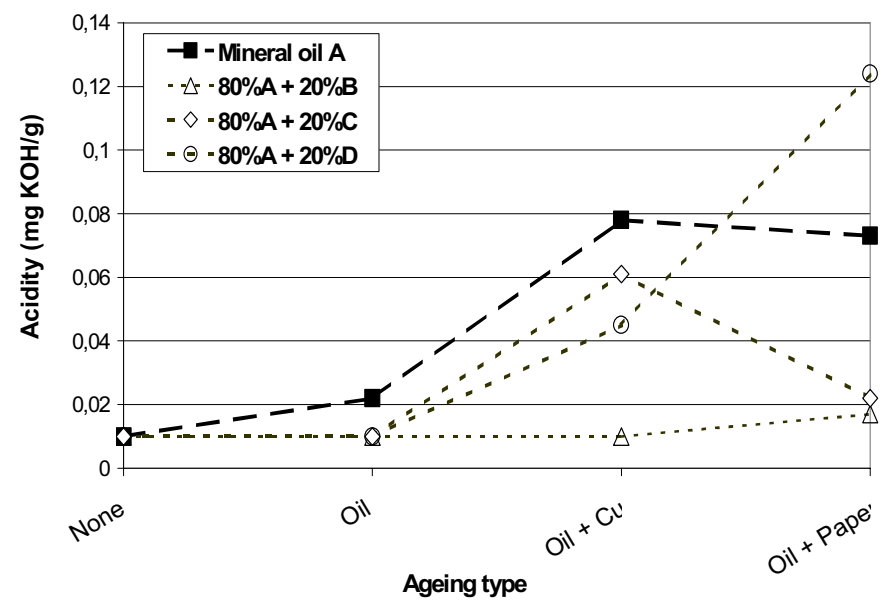

Figure 19. Acidity evolution versus different ageing, for mixtures.

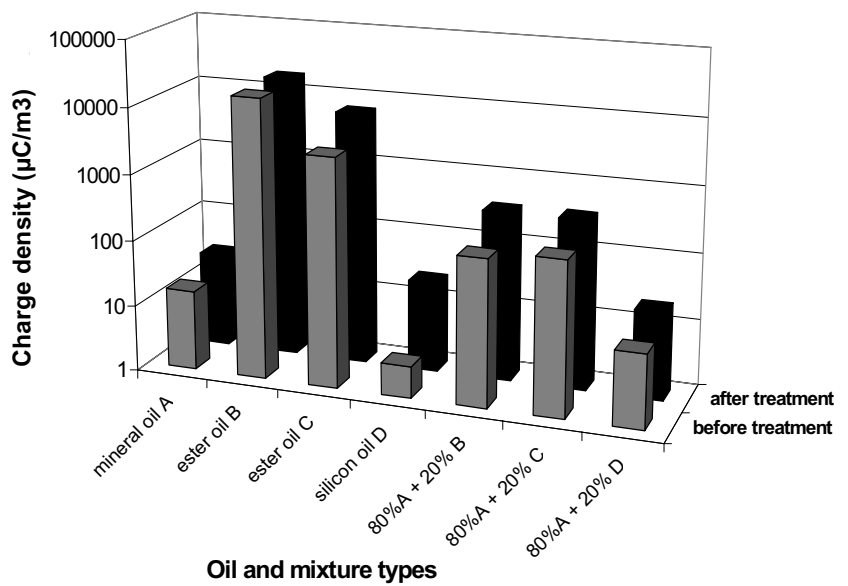

Figure 20. Charge density of oils and mixtures before and after liquid treatment.

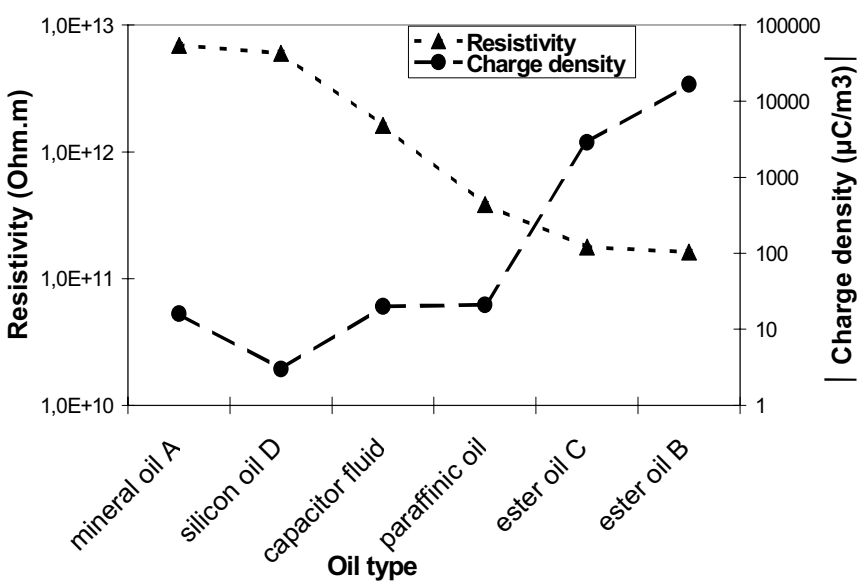

Figure 21. Correlation between charge density / resistivity.

\section{DISCUSSION}

The above results show that each oil has its advantages and its disadvantages. Mineral oil is the most efficient to evacuate heat but it is also the most sensitive to ageing; ester oil enables transformer to have a better breakdown voltage but it presents a higher level of ECT; silicon oil ages slower but it presents the lowest BDV. 
Among the different mixtures we investigated, the mineral oil / $20 \%$ synthetic ester oil mixture appears to be the optimum one from both technical and economical viewpoints. Indeed, synthetic ester oils are four to eight times more expensive than mineral oil. With respect to the technical aspect, the arguments in favour of this mixture are:

(1) Heat transfer: the mineral / $20 \%$ ester oil mixture keeps a viscosity very close to that of mineral oil alone. In addition, the thermal conductivity of ester oil is better than mineral oil. Contrarily to the mixture with ester oil, the mixture with silicon oil reduces the mineral oil viscosity at low temperatures but increases it for transformer operational temperatures.

(2) BDV: ester oil has a better behaviour, due to its better water solubility [12]. And it is remarkable that the addition of $20 \%$ of ester oil to mineral oil considerably improves both the $\mathrm{BDV}$ and the SC, giving results as good as for a mixture with $50 \%$ and for ester oil alone, whatever the product state: new or aged. For a mixture with just $10 \%$ of ester, the BDV is only slightly increased. It seems that there is an interaction between mineral and ester oils, in addition to the water solubility effect that affects these properties. On the other hand, silicon oil has the lowest BDV and it decreases the mineral oil BDV value.

Thus, the addition of $20 \%$ of ester to mineral oil seems to give the most interesting mixture as it improves one critical function of transformer mineral oil (dielectric strength) without degrading its other main function (heat transfer). For that reason, only the results based on mixtures with $20 \%$ are presented and discussed for ageing stability and ECT.

(3) Aging: mineral oil is the most sensitive with a significant increase of acidity and $\tan \delta$, whereas silicon oil is the most resistant. It appears that ester oil, which is in between mineral and silicon oils, has the best effect on the ageing of mineral oil.

(4) ECT: its value is lower when the water content is higher (remaining at a correct value with respect to its water saturation limit) thus confirming the results reported in the literature $[10,16]$. Note that the higher the resistivity, the lower the oil charging tendency is, as shown by other authors $[11,16]$. This last remark explains in part why ester oils and mixtures with mineral oil have a higher ECT.

\section{CONCLUSION}

This work shows that an improvement of the characteristics of power transformers could be achieved via the improvement of the insulating fluid characteristics. In that sense, it appears that the mineral oil / $20 \%$ synthetic ester oil mixture is a good compromise to get a liquid that performs better than mineral oil alone. Indeed, this mixture produces a small change in viscosity, a higher BDV and a better ageing stability than mineral oil alone, and a moderate increase in ECT effect. Thus, either the reliability of existing power transformers could be improved, or the size (and the price) of new power transformers could be decreased by using smaller insulating gaps.

This paper also highlights that: (i) the "mixture law" is not applicable for estimating the "mixture" properties, because of chemical interactions or parameters like water content for the
BDV; (ii) each fluid has one advantage with regard to the others, i.e., mineral oil is the most efficient for the transfer of heat, synthetic ester oil has a good BDV and silicon oil oxidises slower.

\section{ACKNOWLEDGMENT}

The authors would like to express their sincere thanks to $\mathrm{M}$. Saravolac and F. Devaux from AREVA T\&D Power Transformers for their technical and financial supports. A. Darwin from AREVA T\&D is gratefully acknowledged for his reading of the manuscript and fruitful comments. The authors wish to express their gratitude to the Technologies and Materials Laboratory team from Areva Researh Center and especially to J. Porte for his valuable help during the execution of the experiments.

\section{REFERENCES}

[1] T. O. Rouse, "Mineral insulating oil in transformers", IEEE Elect. Insul. Mag., Vol. 14, No. 3, pp. 6-16, 1998.

[2] T. V. Oommen, "Vegetable oils for liquid-filled transformers", IEEE Elect. Insul. Mag., Vol. 18, No. 1, pp. 6-11, 2002.

[3] J. L. Goudie, "Silicon materials in new high temperature liquid transformers designs", Elect. Insul. Conf. Elect. Manuf. Coil Wind., Vol. 23, pp. 455-458, 1997.

[4] Perret, J. and M. Paris, "Silicon oils for transformers (in french)", E.D.F. Bulletin des études et recherches - Série B, Réseaux électriques, Matériels électriques, No. 2, pp. 5-13, 1987.

[5] F. B. Waddington, "New dielectric fluids for power engineering application", GEC J. Sci. Technology, Vol. 49, No. 1, pp. 18-22, 1983.

[6] Ch. Krause, "Dielectric strength of transformer oil, impact of oil flow, moisture and cellulosic particles", WICOR Insulation Conference, Rapperswil (Switzerland), 8p, 1996.

[7] C. Vincent, C. Benoit and R. Olivier, "Comparative evaluation of parameters of the dielectric breakdown test on transformer oil”, IEEE $12^{\text {th }}$ Intern. Conf. Dielectric Liquids (ICDL), Rome, Italy, pp. 337-341, 1996.

[8] V. Prabhashankar and D. J. Badkas, "Mechanism of oxidation of transformers oils", J. of Inst. of Petr., Vol. 47, No. 450, pp. 201-211, 1961.

[9] M. Duval and J. P. Crine, "Dielectric behavior and stabilization of insulating oils in EHV current transformers", IEEE Trans. Elec. Insul., Vol. 20, pp.437-441, 1985.

[10] T. V. Oommen and E. M. Petrie, "Electrostatic charging tendency of transformer oils", IEEE Trans. Power App. Syst., Vol. 103, pp.1923-1931, 1984.

[11] H. Okubo, M. Ikeda, M. Honda and T. Yanari, "Charging tendency measurement of transformer oil", IEEE PES Winter Meeting, A 79 051-4, New York, 1979.

[12] I. Fofana, V. Wasserberg, H. Borsi and E. Gockenbach, "Challenge of mixed insulating liquids for use in high-voltage transformers, Part1: Investigation of mixed liquids", IEEE Elect. Insul. Mag., Vol. 18, No. 3, pp. 18-31, 2002. 
[13] C. Perrier, A. Beroual and J-L. Bessede, "Improvement of power transformers by using mixtures of mineral oil with synthetic esters", IEEE $15^{\text {th }}$ Intern. Conf. Dielectric Liquids (ICDL), Coimbra, Portugal, pp. 389-392, 2005.

[14] J. Lalot, "Statistical processing of dielectric testing methods", E.D.F. Bulletin des études et recherches - Série B, Réseaux électriques, Matériels électriques, No. 1/2, pp. 5-30, 1983.

[15] R. Musil, M. Baur and W. Pfister, "Testing practices for the AC breakdown voltage testing of insulation liquids", IEEE Elect. Insul. Mag., Vol. 11, No.1, pp. 21-25, 1995.

[16] L. Peyraque, A. Béroual, C. Boisdon and F. Buret, "Electrification phenomenon on insulating materials for power transformers (French)", J. Phys. III France 4, pp. 1295-1304, 1994,.

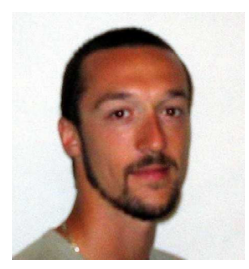

Christophe Perrier was born on 3 April 1978 in Montpellier, France. He obtained his MS degree in insulating materials and the Ph.D. degree in electrical engineering, respectively in 2001 from St Jerôme University of Marseille, and in 2005 from the Ecole Centrale de Lyon, France. He worked as a Ph.D. student at AREVA T\&D (formerly ALSTOM T\&D) and Ecole Centrale de Lyon. He works presently as a research engineer in the Technologies and Materials Laboratory which belongs to the Research Center of AREVA T\&D. He is working on transformers and specifically his topics are insulating oils and Eco-design.

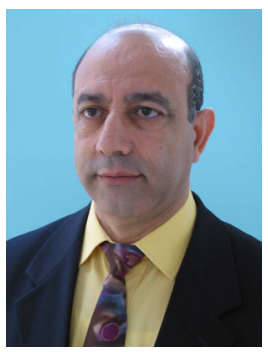

Abderrahmane Beroual (M'92) was born on 30 October 1951. He received the Dipl. Ing. and Ph.D. degrees in electrical engineering, respectively in 1976 from the Ecole Nationale Polytechnique of Algiers, Algeria and in 1979 from the Technical University of Wroclaw, Poland. In 1987, he obtained the Doctorat d'Etat ès Sciences Physiques degree from the Institut National Polytechnique of Grenoble, France. In 1980, he joined the Department of Electrical Engineering at the Ecole Nationale Polytechnique of Algiers. From 1983 to 1987, he was a researcher at the Laboratoire d'Electrostatique et de Matériaux Diélectriques (LEMD) - CNRS of Grenoble, France and associate professor at the Joseph Fourier University of Grenoble. He received the title of professor at the Ecole Nationale Polytechnique of Algiers in 1987. In 1989, he joined the Ecole Centrale de Lyon, France where he is presently professor and the head of the Dielectric Materials and High Voltage team at the Centre de Génie Electrique de Lyon (CEGELY) - CNRS as well as responsible for the Master Research Program in Electrical Engineering. He is responsible of numerous research projects. His main research interests include high voltage insulating, dielectric materials, long air discharge and lightning, modeling of discharges and composites. He is author/co-author of more than 230 papers and four patents. He supervised about $30 \mathrm{Ph} . \mathrm{D}$. theses. He was the leader of the International Study Group on Streamer Propagation in Liquids of the IEEE - DEIS $(1994-1998)$. He is on the International Advisory Committees of the International Conference on Dielectric Liquids and the International Conference on Advances in Processing, Testing and Application of Dielectric Materials.

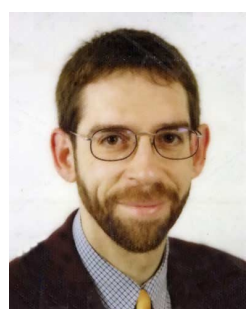

Jean-Luc Bessède (M'96-SM'05) has an Engineer degree (MS) from the National School of Ceramic Engineering from Limoges (France) and a Ph.D. degree in Material Science from the National Institute for Applied Science of Lyon (France). He has worked for four years as research engineer in material science first in the Arsenal of Tarbes (France) then by BSN Emballage in Villeurbanne (France).

He joined the Switchgear Research Center of Alstom T\&D (ARC) (now AREVA T\&D) in 1990 as a research engineer on insulating materials. Since 1991, he has the responsibility of Research \& Development on materials for high voltage circuit breakers and transformers. $\mathrm{He}$ has been Environment Manager of the Switchgear Research Center for three years. He is also in charge of the co-ordination of Eco-design activities within AREVA T\&D. Jean-Luc has already published more than 40 papers either in the field of Material Science \& Engineering or Eco-design. He participated in the set-up of a dozen international Standards and received more than 10 patents. He attended many conferences and was Chair of ICCE 2000 and Chair of the SEE Workshop on Corrosion of Sub-station equipment, Overhead lines and cables in 2001.He is a member of several technical committees as the conferences INSUCON 2002 and INSUCON 2006. 